\title{
Global Prevalence and determinants of preoperative anxiety among surgical patients: A systematic review and Meta-analysis
}

semagn Abate ( $\square$ semmek17@gmail.com )

Dilla University https://orcid.org/0000-0001-5661-8537

\section{Yigrem Chekole}

Dilla University

\section{Bivash Basu}

University of Calcutta - Rajabazar Science College Campus

\section{Research}

Keywords: preoperative, Anxiety, surgery, prevalence, globa

Posted Date: May 19th, 2020

DOI: https://doi.org/10.21203/rs.3.rs-28832/v1

License: (c) (1) This work is licensed under a Creative Commons Attribution 4.0 International License.

Read Full License

Version of Record: A version of this preprint was published at International Journal of Surgery Open on January 1st, 2020. See the published version at https://doi.org/10.1016/j.ijso.2020.05.010. 


\section{Abstract}

Background: Preoperative anxiety, otherwise managed preoperatively, can cause high rate of cardiac mortality, adverse effects during anesthetic induction and patient recovery which correlate with high postoperative pain, increased analgesic and anesthetic consumption, prolonged hospital stay, poor quality of life decrease satisfaction with perioperative care.

Objective: The systematic review and meta-analysis aimed to provide evidence on global prevalence and determinants of preoperative anxiety among surgical patients Methods: A three stage search strategy was conducted on PubMed/Medline, Cochran, Science Direct and LILACS databases. Publication bias was checked with a funnel plot and objective diagnostic test was conducted with Egger's correlation and Begg's regression tests. Results: The global pooled prevalence of preoperative anxiety among surgical patients was 48\% (95\% confidence interval (Cl): 39 to 47\%, 28 studies, 14652 participants. The systematic review and Meta-Analysis revealed that preoperative anxiety was approximately 4 times more likely in patients who had fear of complications, $R R=3.53(95 \%$ confidence interval (Cl: 3.06 to 4.07, six studies).

Conclusion: The review revealed that approximately fifty percent of patients experienced preoperative anxiety which entails the policy makers and health care stakeholders should implement mitigating strategies to prevent and manage preoperative anxiety.

\section{Background}

Anxiety is an emotional state of fear, nervousness, and worry about threatening events associated with the physiological alertness which is accompanied by restlessness, fatigue, problems in concentration, and muscular tension (1-3). Perioperative anxiety is described as a vague, uneasy feeling in which the exact causes are often nonspecific and unknown to the individual but known to cause the body to react with undesirable hemodynamics as a consequence of sympathetic, parasympathetic and endocrine stimulation (1-9).

Anxiety can occur in any person in the acute or chronic form and can affect the perioperative anesthetic management and overall surgical outcomes by increasing Anesthetic requirement, delayed awaking, hemodynamic derangements, postoperative pain, delaying in wound healing, impair immune system response, higher risk of infection $(2,4,6,10-21)$.

The prevalence of preoperative anxiety varies according to the types of surgery, gender, motives for surgery, and country which reaches persistently as high as $97 \%$ (22).

Studies conducted in the European region showed that the prevalence of preoperative anxiety among surgical patients varied from $27-80 \%$ where the highest was observed in Spain and the smallest was in Holland (11, 23-26). 
Studies conducted in India revealed that the prevalence of preoperative anxiety was varied from 47$70.3 \%$ (27-29) while the prevalence of preoperative anxiety in Pakistan was ranged from $62-97 \%(16,22$, 30).

Studies done in the United States of America showed that the prevalence of preoperative anxiety was as high as $20.2 \%(31,32)$ while the prevalence of preoperative anxiety in Brazil was $24 \%(33)$.

Prevalence of preoperative anxiety among surgical patients in Ethiopia was very which varied from 47$70.3 \%(21,34-36)$ and other studies in Africa; Nigeria and Tunisia showed that the prevalence of preoperative anxiety was 51 to $90 \%(10,37,38)$ and $67.5 \%$ respectively(39).

Literature mentioned that preoperative anxiety depends on age, gender, marital status, educational level, fear of postponed of surgery, types of surgery, fear of anesthesia, fear of surgery, fear of awakening in the middle of surgery, financial loss, fear postoperative pain, fear of death and fear of unknown origin $(2,4,6$, $12,25,33,35,36,38-47)$. However, the leading cause of preoperative anxiety frequently mentioned in the literature was the outcomes of surgery which accounted for $(29.3 \%)$ followed by fear of postoperative course (19.5\%) and complications during/after the procedure (11.4\%)(48).

The impacts of preoperative anxiety are numerous which includes acute myocardial infarction, heart failure, pulmonary edema, high readmission rate, poor quality of life and high rate of cardiac mortality which correlate with high postoperative pain, increased analgesic and anesthetic consumption, prolonged hospital stay, adverse influence during anesthetic induction and patient recovery and decrease patient satisfaction with perioperative care $(2-5,7,12,13,25,40-42,44,45,48-58)$.

Mortality and morbidity associated with preoperative anxiety are more likely due to major cardiovascular problems associated with health-related behaviors such as smoking, poor diet, poor compliance with treatment, or an inactive lifestyle and direct influence on the myocardial perfusion, autonomic nervous system regulation, platelet activation, increased hypothalamus-pituitary-adrenal axis activity and exaggerated inflammatory processes $(3,4,7,8,12,13,17,26,41,44,45,50,51,57,59-64)$. However, the body of evidence on global prevalence and determinates of preoperative anxiety among surgical patients is still in demand. Therefore, this Systematic Review and Meta-analysis is intended to provide evidence on global prevalence and determinates of preoperative anxiety among surgical patients.

\section{Methods}

\section{Eligibility criteria}

\section{Types of studies}

All cross-sectional studies assessing the prevalence of preoperative Anxiety among all surgical patients without any language restriction from January 2000 up to January 2020 were incorporated.

\section{Types of participants}


The participants were all patients undergoing surgical procedures under anesthesia.

\section{Outcomes of interest}

The primary outcome of interest was the prevalence of preoperative anxiety among surgical patients. Sociodemographic characteristics, previous anesthetic exposure, fear of death or complications, presence of comorbidities, health professional mistakes or malpractice, awareness under anesthesia, disability, unable to recover from anesthesia, and fear of postoperative pain were determinants of preoperative anxiety.

\section{Context}

This systemic review and Meta-Analysis incorporated all studies conducted globally and reporting the prevalence of preoperative anxiety among surgical patients.

\section{Inclusion criteria}

All cross-sectional studies assessing the prevalence and associated factors of preoperative anxiety among surgical patients from January 2000 to January 2020 without language restriction which were published and unpublished articles conducted globally were included.

\section{Exclusion criteria}

Studies other than cross-sectional studies, studies that didn't report the prevalence of preoperative anxiety, and cross-sectional studies scored less than fifty percent on quality assessment were excluded.

\section{Search strategy}

The search strategy was intended to explore all available published and unpublished studies on the prevalence of preoperative anxiety among surgical patients globally. A three steps search strategy was employed in this review. An initial search on PubMed/Medline, Science direct and LILACS was carried out followed by an analysis of the text words contained in Title/Abstract and indexed terms. A second search was undertaken by combining free text words and indexed terms with Boolean operators. The third search was conducted with the reference lists of all identified reports and articles for additional studies. Finally, the additional and grey literature search was conducted on Google scholars up to ten pages. The result of the search strategy was presented with the Prisma flow chart (Fig. 1).

\section{Data extraction}

The data from each study were extracted by SM and YA independently with Microsoft excel format and imported for analysis in R software version 3.6.1 and STATA version 14. Author, publication year, the mean age of participants, Country, types of surgery, events of preoperative anxiety, sample size, and events in each risk factor for factor analysis were extracted.

\section{Assessment of methodological quality}


Articles identified for retrieval were assessed by two independent Authors for methodological quality before inclusion in the review using a standardized critical appraisal Tool adapted from the Joanna Briggs Institute (supplemental Table 1). The disagreements between the Authors appraising the articles were resolved through discussion. Articles with average scores greater than fifty percent were included for data extraction

\section{Data analysis}

The pooled prevalence of preoperative anxiety was determined with a random effect model as there was no substantial heterogeneity. The Heterogeneity among the included studies was checked with forest plot, $\chi 2$ test, $I^{2}$ test, and the $p$-values. Substantial heterogeneity among the included studies was investigated with subgroup analysis and meta-regression. Sensitivity analysis was done to evaluate the influential studies and further analysis was made after removing the outliers.

Publication bias was checked with a funnel plot and the objective diagnostic test was conducted with Egger's correlation, Begg's regression tests, and Trim and fill method. Furthermore, moderator analysis was carried out to identify the independent predictors of the prevalence of preoperative anxiety among surgical patients. The results were presented based on the Preferred Reporting Items for Systematic Reviews and Meta-Analysis (PRISMA)(65).

\section{Results}

\section{Protocol and registration}

The systematic review and meta-analysis was conducted based on the Preferred Reporting Items for Systematic and Meta-analysis (PRISMA) protocols. This systematic review and meta-analysis was sent for registration in Prospero international prospective register of systematic reviews.

\section{Description of included studies}

A total of 852 articles were identified from different databases as described in the methodology section with the Prisma flow diagram (Fig. 1). Forty-five articles were selected for evaluation after the successive screening. Twenty-eight Articles with 14,652 participants assessing the prevalence and determinants of preoperative anxiety as a primary outcome among surgical patients were included (Table 1 ) and the rest were excluded with reasons (supplemental Table 2).

The included studies were published from 2001-2019 with sample size ranged from 20 to 1447.

The twenty-eight included studies were conducted in Brazil (2 studies), Ethiopia (5 studies), Holland (one study), India (3 studies), Pakistan (4 studies), Iran (1 study), Nigeria (3 studies), Palestine (1 study), Saudi Arabia (1 study), Spain(2 studies), Tunisia(1 study), UK(1 study) and USA(3 studies).

The majority of included studies were conducted on different types of surgical specialties (eighteen studies) while five, two, one, and two studies were conducted on cancer, cardiac, obstetrics, and 
orthopedics respectively.

All most all of the included studies identified the possible risk factors of preoperative anxiety among surgical patients which includes but not limited to gender, age, fear of complication, fear of death, fear of medical mistakes, awakening in the middle of surgery, postoperative pain, financial loss, disability, unable to recover from anesthesia, fear of unexplained origin, unexpected outcomes of operation, and so on. 
Table 1

description of included studies

\begin{tabular}{|c|c|c|c|c|c|c|c|}
\hline Author & Year & event & Sample & country & $\begin{array}{l}\text { Types of } \\
\text { surgery }\end{array}$ & $\begin{array}{l}\text { Quality } \\
\text { score }\end{array}$ & $\begin{array}{l}\mathrm{P}(95 \% \\
\mathrm{Cl})\end{array}$ \\
\hline Asres et al(34) & 2019 & 191 & 407 & Ethiopia & All Surgeries & 8 & $\begin{array}{l}47(42, \\
52)\end{array}$ \\
\hline Getachew et al(66) & 2019 & 133 & 237 & Ethiopia & All Surgeries & 7 & $\begin{array}{l}56(50, \\
62)\end{array}$ \\
\hline Khalili et al(67) & 2019 & 109 & 231 & Iran & All Surgeries & 6 & $\begin{array}{l}47(41, \\
54)\end{array}$ \\
\hline Zeb A et al(30) & 2019 & 17 & 70 & Pakistan & All Surgeries & 5 & $\begin{array}{l}24(16, \\
35)\end{array}$ \\
\hline Majumdar et al (32) & 2019 & 1447 & 8665 & America & cancer & 7 & $\begin{array}{l}17(16 \\
17)\end{array}$ \\
\hline José et al (26) & 2019 & 48 & 60 & Spain & cardiac & 5 & $\begin{array}{l}80(68, \\
88)\end{array}$ \\
\hline $\begin{array}{l}\text { Woldegerima et } \\
\mathrm{al}(21)\end{array}$ & 2018 & 106 & 178 & Ethiopia & All Surgeries & 6 & $\begin{array}{l}60(52, \\
66)\end{array}$ \\
\hline Mulugeta et al(35) & 2018 & 215 & 353 & Ethiopia & All Surgeries & 9 & $\begin{array}{l}61(56, \\
66)\end{array}$ \\
\hline Tajgna et al(68) & 2018 & 140 & 160 & India & All Surgeries & 5 & $\begin{array}{l}88(58, \\
68)\end{array}$ \\
\hline Arshi et al(69) & 2018 & 228 & 363 & Pakistan & All Surgeries & 5 & $\begin{array}{l}63(58, \\
68)\end{array}$ \\
\hline Mellouli et al (39) & 2018 & 224 & 332 & Tunisia & All Surgeries & 6 & $\begin{array}{l}67(62, \\
72)\end{array}$ \\
\hline Edipoglu et al(11) & 2018 & 221 & 499 & Turkish & All Surgeries & 6 & $\begin{array}{l}44(40, \\
49)\end{array}$ \\
\hline Ya'akba et al(70) & 2017 & 184 & 320 & Palestine & All Surgeries & 6 & $\begin{array}{l}57(52, \\
63)\end{array}$ \\
\hline Bansal et al(27) & 2017 & 110 & 200 & India & Obstetrics & 5 & $\begin{array}{l}55(48, \\
62)\end{array}$ \\
\hline Palazón et al(7) & 2017 & 56 & 200 & Spain & cardiac & 8 & $\begin{array}{l}28(22, \\
35)\end{array}$ \\
\hline Saini et al(28) & 2016 & 129 & 219 & India & All Surgeries & 5 & $\begin{array}{l}59(52, \\
65)\end{array}$ \\
\hline Le Xu et al(71) & 2016 & 11 & 53 & China & cancer & 5 & $\begin{array}{l}21(12, \\
33)\end{array}$ \\
\hline
\end{tabular}




\begin{tabular}{|c|c|c|c|c|c|c|c|}
\hline Author & Year & event & Sample & country & $\begin{array}{l}\text { Types of } \\
\text { surgery }\end{array}$ & $\begin{array}{l}\text { Quality } \\
\text { score }\end{array}$ & $\begin{array}{l}\mathrm{P}(95 \% \\
\mathrm{Cl})\end{array}$ \\
\hline Adesanmi et al(10) & 2015 & 26 & 51 & Nigeria & All Surgeries & 5 & $\begin{array}{l}51(38, \\
64)\end{array}$ \\
\hline $\begin{array}{l}\text { Hellstadius et } \\
\text { al(25) }\end{array}$ & 2015 & 36 & 106 & UK & cancer & 8 & $\begin{array}{l}34(26, \\
43)\end{array}$ \\
\hline Nigussie et al(36) & 2014 & 168 & 239 & Ethiopia & All Surgeries & 7 & $\begin{array}{l}70(64, \\
76)\end{array}$ \\
\hline $\begin{array}{l}\text { Gangadharan et } \\
\text { al(60) }\end{array}$ & 2014 & 12 & 20 & $\begin{array}{l}\text { Saudi } \\
\text { Arabia }\end{array}$ & All Surgeries & 5 & $\begin{array}{l}60(39 \\
78)\end{array}$ \\
\hline Santos et al(72) & 2014 & 16 & 41 & Brazil & cancer & 5 & $\begin{array}{l}39(26, \\
54)\end{array}$ \\
\hline $\begin{array}{l}\text { Duivenvoorden et } \\
\text { al(23) }\end{array}$ & 2013 & 79 & 282 & Holland & Orthopedics & 6 & $\begin{array}{l}28(23, \\
34)\end{array}$ \\
\hline Ebirim et al(38) & 2010 & 43 & 125 & Nigeria & All Surgeries & 5 & $\begin{array}{l}34(27 \\
43)\end{array}$ \\
\hline Daniel et al(31) & 2010 & 58 & 287 & America & Orthopedics & 6 & $\begin{array}{l}20(16, \\
25)\end{array}$ \\
\hline Jafar et al(16) & 2009 & 186 & 300 & Pakistan & All Surgeries & 5 & $\begin{array}{l}62(56, \\
67)\end{array}$ \\
\hline Palpattu et al(73) & 2004 & 28 & 62 & USA & cancer & 6 & $\begin{array}{l}45(33, \\
57)\end{array}$ \\
\hline Caumo et al(33) & 2001 & 141 & 592 & Brazil & All Surgeries & 8 & $\begin{array}{l}24(21, \\
27)\end{array}$ \\
\hline
\end{tabular}

\section{Meta-Analysis}

This systematic review and Meta-Analysis was intended to provide evidence on the global prevalence of preoperative anxiety and its determents among surgical patients. All of the included studies reported the prevalence of preoperative anxiety among surgical patients.

The global pooled prevalence of preoperative anxiety among surgical patients was $48 \%$ ( $95 \%$ confidence interval (Cl): 39 to $47 \%, 28$ studies, 14652 participants (Fig. 2).

The subgroup analysis by continent revealed that preoperative prevalence of anxiety among surgical patient was the highest in African continent 56\% (95\% confidence interval(Cl): 48 to 64, 8 studies, 1922 participants followed by Asian continent 54\% (95\% confidence interval(Cl): 43 to 65, 10 studies, 1936 participants). Whereas the lowest prevalence of preoperative anxiety was seen in North America $24 \%$ (95\% confidence interval (Cl): 16 to 33, three studies, 633 participants) followed by Latin America 25\% (95\% confidence interval (Cl): 21 to 28, two studies, 9014 participants) (Fig. 3). 
Subgroup analysis revealed that preoperative anxiety among surgical patients by country was the highest in India $67 \%$ (95\% confidence interval (Cl): 46 to 89, three studies, 579 participants) followed by Tunisia 67\% (95\% confidence interval (Cl): 62 to 72, one study, 332 participants), Saudi Arabia 60\% (95\% confidence interval(Cl): 36 to 81, one study, 20 participants), Ethiopia 59\% (95\% confidence interval (Cl): 51 to 67 , five studies, 1414 participants), Palestine 57\% (95\% confidence interval (Cl): 52 to 63, one study, 320 participants) and Pakistan 50\% (95\% confidence interval(Cl): 32 to 69, three studies, 733 participants) and whereas the lowest which is less than fifty percent was found in China $21 \%$ (95\% confidence interval (Cl): 11 to 32, one study, 53 participants), America 24\% (95\% confidence interval (Cl): 16 to 34 , three studies, 9014 participants), Brazil 25\%(21 to 28, two studies, 633 participants), Holland $28 \%$ (95\% confidence interval (Cl): 23 to 34 , one study, 282 participants), UK $34 \%$ (95\% confidence interval (Cl): 25 to 44, one study, 36 participants), Nigeria 39\% (95\% confidence interval (Cl):32 to 46, 175 participants) and Turkey 44\%(95\% confidence interval (CI):40 to 39,one study, 499 participants) (supplemental Fig. 1).

Subgroup analysis by types of surgery revealed that the prevalence of anxiety was the highest in obstetric patients 55\% ( (95\% confidence interval (Cl): 48 to 62$)$ : one study, 200 participants) followed by studies with different types of surgical specialty patients $54 \%$ (95\% confidence interval (CI): 46 to 63,18 studies, 4696 participants), cardiac patients $42 \%$ (95\% confidence interval (Cl): 37 to 48, two studies, 260 participants) while the lowest was seen in cancer patients 30\% (95\% confidence interval (Cl): 18 to 42 , five studies, 8927 studies) followed by orthopedics $24 \%$ (95\% confidence interval (Cl): 20 to 27, two studies, 569 participants) (Fig. 4).

The funnel plot for evaluation of publication bias didn't show asymmetric funnel plot. Besides, the rank correlation and Egger's regression test didn't show a significant difference for small study effect ( $p$-value $>0.05$ ) (supplemental Fig. 2).

\section{Determinants of preoperative Anxiety}

Literature mentioned different types of risk factors of preoperative anxiety among surgical patients despite the presence of inconclusive evidence on the major independent predictors of anxiety. The most commonly mentioned risk factors of preoperative anxiety among surgical patients including but not limited to gender, age, fear of complication, fear of death, fear of medical mistakes, awakening in the middle of surgery, postoperative pain, financial loss, disability, unable to recover from anesthesia, fear of unexplained origin, and unexpected outcomes of the operation.

The systematic review and Meta-Analysis revealed that preoperative anxiety was approximately 4 times more likely in patients who had fear of complications, $\mathrm{RR}=3.53$ (95\% confidence interval (Cl: 3.06 to 4.07 , six studies). The systematic review also showed that the risks of preoperative anxiety among surgical patients increased by eighty-two percent in females as compared to male patients, RR $=1.18(95 \%$ confidence interval(Cl): 1.10 to $1.27,12$ studies). 
The systematic review also showed that the risks of developing preoperative anxiety among surgical patients were associated with patients perceived perception of awakening in the middle of surgery, fear of medical mistakes, and postoperative pain: $\mathrm{RR}=2.58$ (95\% confidence interval $(\mathrm{Cl}): 2.17$ to $3.06,4$ studies), $R R=1.93$ (95\% confidence interval ( $\mathrm{Cl}$ ): 1.57 to $2.36,2$ studies) and $\mathrm{RR}=1.43$ (95\% confidence interval (Cl): 1.31 to $1.56,4$ studies) respectively. However, history of previous anesthesia or surgical exposure reduced the risks of developing preoperative anxiety among patients by eighteen percent, RR = 0.88(95\% confidence interval (Cl): 0.82 to $0.95,9$ studies) (Fig. 5 ).

\section{Discussion}

The preoperative anxiety among surgical patients is not routinely performed as part of preoperative patient evaluation and preparation for Anesthesia and surgery $(5,74-77)$. However, body of evidences revealed that preoperative anxiety contributed a huge impact on perioperative undesirable outcomes including increased doses of induction agents $(11,22,78,79)$, hemodynamic instability $(11,22,27,52,79)$, cardiac morbidity and mortality in high risk patients $(26,51,64,80,81)$, postoperative pain and increased consumption of analgesics(18, 72, 74, 78, 82-86), postoperative delirium(87), patient dissatisfaction(88$91)$, increased hospital length of $\operatorname{stay}(29,89,92)$ and these in turn can incur a significant health care $\operatorname{cost}(1,86,89,92)$.

This systematic review and Meta-analysis was aimed to provide evidence on global preoperative anxiety and its determinants among surgical patients for different stakeholders to mitigate strategies to prevent preoperative anxiety and associated undesirable outcomes.

The pooled global prevalence of preoperative anxiety among surgical patients was unexpectedly very high $48 \%$ (95\% confidence interval (Cl): 39 to 47\%, 28 studies, 14652 participants).

The subgroup analysis by continent revealed that preoperative anxiety was the highest in African continent 56\% (95\% confidence interval (Cl): 48 to 64,8 studies, 1922 participants followed by Asian $54 \%$ (95\% confidence interval (Cl): 43 to 65, 10 studies, 1936 participants) as compared to the rest of the world. This discrepancy might be due to the inclusion of several studies conducted in Africa and Asia. Another possible explanation might be low awareness about anesthesia, surgery, and postoperative pain management options in these continents because the majority of populations reside in the countryside where there are limited infrastructure and access to health information.

The Meta-Analysis revealed that the prevalence of preoperative anxiety was the highest in the obstetric patient(27) followed by other major surgical $(11,16,21,30,35,36,38,67,69)$ and cardiac surgery patients $(7,26)$ while the lowest was seen in cancer patients $(25,32,71-73)$. These variations can be explained by two lives in the obstetric patient, a small number of included studies, and inclusion of heterogeneous groups in studies with all surgical patients. The lower prevalence of preoperative anxiety among cancer patients mighty is because these patients had already known the outcomes of their disease prognosis and the felt they did not worry anymore. 
The Meta-Analysis showed that fear of complication RR=3.53(95\% confidence interval (Cl):3.06 to 4.07), being female $\mathrm{RR}=1.18$ (95\% confidence interval ( $\mathrm{Cl}): 1.10$ to1.27), fear of awakening in the middle of surgery 2.58 (95\% confidence interval (CI): 2.17 to 3.06), fear of medical mistakes RR= 1.93 (95\% confidence interval (Cl): 1.57 to 2.36 ) and fear of postoperative pain $\mathrm{RR}=1.43$ (95\% confidence interval (Cl): 1.31 to 1.56) were the major independent predictors of preoperative anxiety. This finding is similar to the findings of the included studies.

Previous anesthesia or surgical exposure showed a significant reduction in preoperative anxiety among surgical patients and this finding is in line with the findings of the included studies. This could be explained as patients had opportunities to know about the operation theatre environment, about types of anesthesia and surgery, postoperative pain.

\section{Quality of evidence}

The systematic review and meta-analysis included plenty of studies with adequate sample size. The methodological quality of included studies was moderate to high quality as depicted with Joanna Briggs Institute assessment tool for meta-analysis of cross-sectional studies. However, substantial heterogeneity associated with dissimilarities of included studies in surgical specialty, settings, location, and anxiety assessment tools which entail further observational and randomized controlled trials by controlling potential confounders.

\section{Limitation of the study}

The review incorporated plenty of studies with a large number of participants but the majority of studies included in this review didn't report risk determinants for factor analysis. The included studies were conducted in a different setting, surgical specialty, and population which caused substantial heterogeneity. Besides, there were a limited number of studies in some countries and it would be difficult to provide conclusive evidence with results pooled from fewer studies.

\section{Implication for practice}

Body of evidence revealed that preoperative anxiety among surgical patients significantly affects perioperative patients' outcomes particularly in high-risk patients including patients with cardiac disease, hypertension, diabetes mellitus, advanced age, pre-existing psychological disorders, or susceptible to anxiety. However, preoperative anxiety assessment is not routinely practiced as part of preoperative evaluation and preparation for surgery. Therefore, preoperative anxiety screening, patient education on how to reduce anxiety, awareness creation about anesthesia and surgery, and postoperative pain management options should be incorporated in preoperative patient evaluation and preparation period. 


\section{The implication for further research}

The Meta-analysis revealed that preoperative anxiety among surgical patients was very high and the major independent predictors of preoperative anxiety were traced. However, the included studies were too heterogeneous, and cross-sectional studies also don't show a temporal relationship of preoperative anxiety and its determinants. Therefore, further observational and randomized controlled trials are in demand for a specific group of surgical patients by stratifying the possible independent predictors.

\section{Conclusion}

The global prevalence of preoperative anxiety among surgical patients was very high which entails special attention. The Meta-Analysis revealed that the prevalence of preoperative anxiety was the highest in Africa followed by Asia while the lowest was seen in North America followed by Latin America and Europe.

The Meta-analysis showed that fear of complication, gender, fear of medical mistakes, fear of awakening during surgery and fear of postoperative pain were independent predictors of preoperative anxiety while previous Anesthesia or surgical experience showed a significant reduction in preoperative anxiety and this, in turn, reminds the health care providers, preoperative education and information about the perioperative situations may reduce preoperative anxiety.

\section{Abbreviations}

Cl: Confidence Interval; ES: effect size; LILACS: Latin American and Caribbean on Health Sciences Literature; PRISMA: Preferred Reporting Items for Systematic Reviews and Meta-Analyses; RR: Relative Risk

\section{Declarations}

Ethics approval and consent to participate

Not applicable

Consent for publication

Not applicable

Registration

This umbrella review was submitted for registration in Prospero international prospective register of systemic reviews.

Availability of data and materials 
Data and material can be available where appropriate.

Competing interests

The authors declare that there are no competing interests

Funding

No funding was obtained from any organization

Authors' contributions

AS and AC conceived the idea and design the study. All the Authors involved in searching strategy, data extraction, quality assessment, analysis and manuscript preparation. All Authors have read and approved the manuscript.

Acknowledgments

The authors would like to acknowledge Dilla University for technical support and encouragement to carry out the project.

\section{References}

1. Almalki MS, Hakami OAO, Al-Amri AM. Assessment of preoperative anxiety among patients undergoing elective surgery. The Egyptian Journal of Hospital Medicine. 2017;69(4):2329-33.

2. Sigdel S. Perioperative anxiety: A short review. Glob Anaesth Perioper Med. 2015;1(10.15761).

3. Stamenkovic DM, Rancic NK, Latas MB, Neskovic V, Rondovic GM, Wu JD, et al. Preoperative anxiety and implications on postoperative recovery: what can we do to change our history. Minerva Anestesiol. 2018;84(11):1307-17.

4. Bradt J, Dileo C, Potvin N. Music for stress and anxiety reduction in coronary heart disease patients. Cochrane Database of Systematic Reviews. 2013(12).

5. Carneiro AF, Mathias LAST, Júnior AR, de Morais NS, Gozzani JL, de Miranda AP. Evaluation of preoperative anxiety and depression in patients undergoing invasive cardiac procedures. Brazilian Journal of Anesthesiology. 2009;59(4):431-8.

6. Ghimire R, Poudel P. Preoperative Anxiety and Its Determinants Among Patients Scheduled for Major Surgery: A Hospital Based Study. Journal of Anesthesiology. 2018;6(2):57-60.

7. Hernández-Palazón J, Fuentes-García D, Falcón-Araña L, Roca-Calvo MJ, Burguillos-López S, Doménech-Asensi $\mathrm{P}$, et al. Assessment of preoperative anxiety in cardiac surgery patients lacking a history of anxiety: contributing factors and postoperative morbidity. J Cardiothorac Vasc Anesth. 2018;32(1):236-44.

8. Theunissen M, Peters ML, Bruce J, Gramke H-F, Marcus MA. Preoperative anxiety and catastrophizing: a systematic review and meta-analysis of the association with chronic postsurgical 
pain. Clin J Pain. 2012;28(9):819-41.

9. Valenzuela JM, Barrera JS, Ornelas JA. Anxiety in preoperative anesthetic procedures. Cir Cir. 2010;78(2):147-51.

10. Akinsulore A, Owojuyigbe AM, Faponle AF, Fatoye FO. Assessment of preoperative and postoperative anxiety among elective major surgery patients in a tertiary hospital in Nigeria. Middle East $\mathrm{J}$ Anaesthesiol. 2015;23(2):235-40.

11. Celik F, Edipoglu IS. Evaluation of preoperative anxiety and fear of anesthesia using APAIS score. European journal of medical research. 2018;23(1):41.

12. Chow CH, Van Lieshout RJ, Schmidt LA, Dobson KG, Buckley N. Systematic review: audiovisual interventions for reducing preoperative anxiety in children undergoing elective surgery. J Pediatr Psychol. 2016;41(2):182-203.

13. Cserép Z, Losoncz E, Balog P, Szili-Török T, Husz A, Juhász B, et al. The impact of preoperative anxiety and education level on long-term mortality after cardiac surgery. J Cardiothorac Surg. 2012;7(1):86.

14. Erkilic E, Kesimci E, Soykut C, Doger C, Gumus T, Kanbak O. Factors associated with preoperative anxiety levels of Turkish surgical patients: from a single center in Ankara. Patient Prefer Adherence. $2017 ; 11: 291$.

15. Festini F, Liguori S, Stacchini M, Ciofi D, Giusti F, Olivini N, et al. 0-143 effectiveness of a new method to reduce preoperative anxiety in children: randomised controlled trial. BMJ Publishing Group Ltd; 2014.

16. Jafar MF, Khan FA. Frequency of preoperative anxiety in Pakistani surgical patients. J Pak Med Assoc. 2009;59(6):359.

17. Rasouli MR, Menendez ME, Sayadipour A, Purtill JJ, Parvizi J. Direct cost and complications associated with total joint arthroplasty in patients with preoperative anxiety and depression. J Arthroplast. 2016;31(2):533-6.

18. Robleda G, Sillero-Sillero A, Puig T, Gich I, Baños J-E. Influence of preoperative emotional state on postoperative pain following orthopedic and trauma surgery. Rev Latinoam Enferm. 2014;22(5):78591.

19. Ruis C, Wajer IH, Robe P, van Zandvoort M. Anxiety in the preoperative phase of awake brain tumor surgery. Clinical neurology neurosurgery. 2017;157:7-10.

20. Seto M, Sakamoto Y, Takahashi H, Kita R, Kikuta T. Does planned intravenous sedation affect preoperative anxiety in patients? Int J Oral Maxillofac Surg. 2013;42(4):497-501.

21. Woldegerima Y, Fitwi G, Yimer H, Hailekiros A. Prevalence and factors associated with preoperative anxiety among elective surgical patients at University of Gondar Hospital. Gondar, Northwest Ethiopia, 2017. A cross-sectional study. International Journal of Surgery Open. 2018;10:21-9.

22. Maheshwari D, Ismail S. Preoperative anxiety in patients selecting either general or regional anesthesia for elective cesarean section. J Anaesthesiol Clin Pharmacol. 2015;31(2):196. 
23. Duivenvoorden T, Vissers M, Verhaar J, Busschbach J, Gosens T, Bloem R, et al. Anxiety and depressive symptoms before and after total hip and knee arthroplasty: a prospective multicentre study. Osteoarthritis Cartilage. 2013;21(12):1834-40.

24. Ekinci M, Gölboyu BE, Dülgeroğlu O, Aksun M, Baysal PK, Çelik EC, et al. The relationship between preoperative anxiety levels and vasovagal incidents during the administration of spinal anesthesia. Revista brasileira de anestesiologia. 2017;67(4):388-94.

25. Hellstadius Y, Lagergren J, Zylstra J, Gossage J, Davies A, Hultman C, et al. Prevalence and predictors of anxiety and depression among esophageal cancer patients prior to surgery. Dis Esophagus. 2016;29(8):1128-34.

26. Prado-Olivares J, Chover-Sierra E. Preoperatory Anxiety in Patients Undergoing Cardiac Surgery. Diseases. 2019;7(2):46.

27. Bansal T, Joon A. A comparative study to assess preoperative anxiety in obstetric patients undergoing elective or emergency cesarean section. Anaesthesia, Pain \& Intensive Care. 2019:25-30.

28. Saini S, Dayal M. Preoperative Anxiety in Indian Surgical Patients-Experience of a Single Unit. Indian J Appl Res. 2016;6(9):476-9.

29. Vadhanan P, Tripaty DK, Balakrishnan K. Pre-operative anxiety amongst patients in a tertiary care hospital in India-a prevalence study. Journal of Society of Anesthesiologists of Nepal. 2017;4(1):510.

30. Zeb A, Hammad AM, Baig R, Rahman S. Pre-Operative Anxiety in Patients at Tertiary Care Hospital, Peshawar. Pakistan J Clin Trials Res. 2019;2(2):76-80.

31. Riddle DL, Wade JB, Jiranek WA. Major depression, generalized anxiety disorder, and panic disorder in patients scheduled for knee arthroplasty. J Arthroplast. 2010;25(4):581-8.

32. Majumdar JR, Vertosick EA, Cohen B, Assel M, Levine M, Barton-Burke M. Preoperative Anxiety in Patients Undergoing Outpatient Cancer Surgery. Asia-Pacific Journal of Oncology Nursing. 2019;6(4):440.

33. Caumo W, Schmidt AP, Schneider CN, Bergmann J, Iwamoto C, Bandeira D, et al. Risk factors for preoperative anxiety in adults. Acta Anaesthesiol Scand. 2001;45(3):298-307.

34. Bedaso A, Ayalew M. Preoperative anxiety among adult patients undergoing elective surgery: a prospective survey at a general hospital in Ethiopia. Patient safety in surgery. 2019;13(1):18.

35. Mulugeta H, Ayana M, Sintayehu M, Dessie G, Zewdu T. Preoperative anxiety and associated factors among adult surgical patients in Debre Markos and Felege Hiwot referral hospitals, Northwest Ethiopia. BMC anesthesiology. 2018;18(1):155.

36. Nigussie S, Belachew T, Wolancho W. Predictors of preoperative anxiety among surgical patients in Jimma University specialized teaching hospital, South Western Ethiopia. BMC Surg. 2014;14(1):67.

37. Dagona SS. Prevalence of preoperative anxiety among Hausa patients undergoing elective surgery-a descriptive study. Advances in Social Sciences Research Journal. 2018;5(11). 
38. Ebirim L, Tobin M. Factors responsible for pre-operative anxiety in elective surgical patients at a university teaching hospital: A pilot study. The internet journal of Anesthesiology. 2010;29(2):1-6.

39. Zammit N, Menel M, Rania F. Preoperative Anxiety in the Tertiary Care Hospitals of Sousse, Tunisia: Prevalence and Predictors. SOJ Surgery. 2018;5(1):1-5.

40. Alves M, Pimentel A, Guaratini A, Marcolino J, Gozzani J, Mathias L. Preoperative anxiety in surgeries of the breast: a comparative study between patients with suspected breast cancer and that undergoing cosmetic surgery. Revista brasileira de anestesiologia. 2007;57(2):147-56.

41. Choinière $M$, Watt-Watson J, Victor JC, Baskett RJ, Bussières JS, Carrier M, et al. Prevalence of and risk factors for persistent postoperative nonanginal pain after cardiac surgery: a 2-year prospective multicentre study. Cmaj. 2014;186(7):E213-E23.

42. Chunhui L, Ju-Xiang L, Hai S, Weitong H, Qiang P, Xiaoshu C. ASSA13-14-26 Preoperative Anxiety is Associated with Higher Blood Pressure in Patients Waiting For Surgery. Heart. 2013;99(Suppl 1):A66A.

43. de Oliveira Cumino D, Cagno G, Gonçalves VFZ, Wajman DS, Mathias LAdST. Impact of preanesthetic information on anxiety of parents and children. Brazilian Journal of Anesthesiology (English Edition). 2013;63(6):473-82.

44. De Oliveira Jr GS, Holl JL, McCarthy RJ, Butt ZA, Nouriel J, McCaffery K, et al. Overestimation of mortality risk and preoperative anxiety in patients undergoing elective general surgery procedures: a propensity matched analysis. Int J Surg. 2014;12(12):1473-7.

45. Fathi M, Alavi SM, Joudi M, Joudi M, Mahdikhani H, Ferasatkish R, et al. Preoperative anxiety in candidates for heart surgery. Iranian journal of psychiatry behavioral sciences. 2014;8(2):90.

46. Goebel S, Kaup L, Mehdorn HM. Measuring preoperative anxiety in patients with intracranial tumors: the Amsterdam preoperative anxiety and information scale. J Neurosurg Anesthesiol. 2011;23(4):297-303.

47. Moura LAd, Dias IMG, Pereira LV. Prevalence and factors associated with preoperative anxiety in children aged 5-12 years. Revista latino-americana de enfermagem. 2016;24.

48. Kuzminskaitè V, Kaklauskaitė J, Petkevičiūtè J. Incidence and features of preoperative anxiety in patients undergoing elective non-cardiac surgery. Acta medica Lituanica. 2019;26(1):93.

49. Grabow L, Buse R. Preoperative anxiety-anxiety about the operation, anxiety about anesthesia, anxiety about pain? Psychotherapie. Psychosomatik medizinische Psychologie. 1990;40(7):255-63.

50. Gu G, Zhou Y, Zhang Y, Cui W. Increased prevalence of anxiety and depression symptoms in patients with coronary artery disease before and after percutaneous coronary intervention treatment. BMC Psychiatry. 2016;16(1):259.

51. Joseph HK, Whitcomb J, Taylor W. Effect of anxiety on individuals and caregivers after coronary artery bypass grafting surgery: a review of the literature. Dimensions of Critical Care Nursing. 2015;34(5):285-8.

52. Kim W-S, Byeon G-J, Song B-J, Lee HJ. Availability of preoperative anxiety scale as a predictive factor for hemodynamic changes during induction of anesthesia. Korean journal of anesthesiology. 
2010;58(4):328.

53. Korbmacher B, Ulbrich S, Dalyanoglu H, Lichtenberg A, Schipke J, Franz M, et al. Perioperative and long-term development of anxiety and depression in CABG patients. Thorac Cardiovasc Surg. 2013;61(08):676-81.

54. Liu X-Y, Ma Y-K, Zhao J-C, Wu Z-P, Zhang L, Liu L-H. Risk factors for preoperative anxiety and depression in patients scheduled for abdominal aortic aneurysm repair. Chin Med J. 2018;131(16):1951.

55. Ocalan R, Akin C, Disli Z, Kilinc T, Ozlugedik S. Preoperative anxiety and postoperative pain in patients undergoing septoplasty. B-ent. 2015;11(1):19-23.

56. Perks A, Chakravarti S, Manninen P. Preoperative anxiety in neurosurgical patients. J Neurosurg Anesthesiol. 2009;21(2):127-30.

57. Stundner O, Kirksey M, Chiu YL, Mazumdar M, Poultsides L, Gerner P, et al. Demographics and perioperative outcome in patients with depression and anxiety undergoing total joint arthroplasty: a population-based study. Psychosomatics. 2013;54(2):149-57.

58. Sukegawa A, Miyagi E, Asai-Sato M, Saji H, Sugiura K, Matsumura T, et al. Anxiety and prevalence of psychiatric disorders among patients awaiting surgery for suspected ovarian cancer. Journal of Obstetrics Gynaecology Research. 2008;34(4):543-51.

59. Detroyer E, Dobbels F, Verfaillie E, Meyfroidt G, Sergeant P, Milisen K. Is preoperative anxiety and depression associated with onset of delirium after cardiac surgery in older patients? A prospective cohort study. J Am Geriatr Soc. 2008;56(12):2278-84.

60. Gangadharan P, Assiri AM, Assiri AA. Evaluating the level of anxiety among pre-operative patients before elective surgery at selected hospitals in kingdom of saudi arabia. International Journal of Current Research Review. 2014;6(22):37.

61. Kalogianni A, Almpani P, Vastardis L, Baltopoulos G, Charitos C, Brokalaki H. Can nurse-led preoperative education reduce anxiety and postoperative complications of patients undergoing cardiac surgery? European Journal of Cardiovascular Nursing. 2016;15(6):447-58.

62. Tully PJ, Baker RA, Knight JL. Anxiety and depression as risk factors for mortality after coronary artery bypass surgery. J Psychosom Res. 2008;64(3):285-90.

63. Van den Bosch JE, Moons KG, Bonsel GJ, Kalkman CJ. Does measurement of preoperative anxiety have added value for predicting postoperative nausea and vomiting? Anesthesia Analgesia. 2005;100(5):1525-32.

64. Williams JB, Alexander KP, Morin J-F, Langlois Y, Noiseux N, Perrault LP, et al. Preoperative anxiety as a predictor of mortality and major morbidity in patients aged $>70$ years undergoing cardiac surgery. The American journal of cardiology. 2013;111(1):137-42.

65. Moher D, Liberati A, Tetzlaff J, Altman DG. Preferred reporting items for systematic reviews and meta-analyses: the PRISMA statement. Int J Surg. 2010;8(5):336-41.

66. Getachew Takele AN. Daniel Ayelegne and Berhanu Boru. Preoperative Anxiety and its Associated Factors among Patients Waiting Elective Surgery in St. Luke's Catholic Hospital and Nursing College, 
Woliso, Oromia, Ethiopia, 2018. EC EMERGENCY MEDICINE AND CRITICAL CARE. 2019;4(1):21-7.

67. Khalili N, Karvandian K, Ardebili HE, Eftekhar N, Nabavian O. Predictive Factors of Preoperative Anxiety in the Anesthesia Clinic: A Survey of 231 Surgical Candidates. Archives of Anesthesia and Critical Care. 2019.

68. p TKaK. Assessment of Preoperative Depression, Anxiety and Stress for Patients Awaiting Surgery in a Tertiary Care Hospital. Scholars Journal of Applied Medical Sciences. 2018;6(12):4820-6.

69. Kanwal A, Asghar A, Ashraf A, Qadoos A. Prevalence Of Preoperative Anxiety And Its Causes Among Surgical Patients Presenting In Rawalpindi Medical University And Allied Hospitals, Rawalpindi. Journal of Rawalpindi Medical College. 2018;22(S-2):64-7.

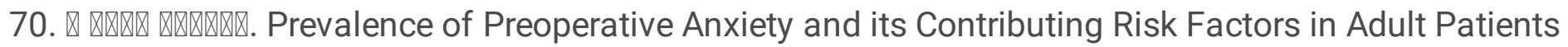
Undergoing Elective Surgery: An-Najah National University; 2017.

71. Xu L, Pan Q, Lin R. Prevalence rate and influencing factors of preoperative anxiety and depression in gastric cancer patients in China: Preliminary study. J Int Med Res. 2016;44(2):377-88.

72. SANTOS LJF, GARCIA JBdS PACHECOJS, ÉBdM VIEIRA, AMd SANTOS. Quality of life, pain, anxiety and depression in patients surgically treated with cancer of rectum. ABCD Arquivos Brasileiros de Cirurgia Digestiva (São Paulo). 2014;27(2):96-100.

73. Palapattu GS, Haisfield-Wolfe ME, Walker JM, Brintzenhofeszoc K, Trock B, Zabora J, et al. Assessment of perioperative psychological distress in patients undergoing radical cystectomy for bladder cancer. The Journal of urology. 2004;172(5):1814-7.

74. Yumul R, Ahdout J, Goodman A, Lazo OLE, Conte AH, Cook-Wiens G, et al. Assessment Of Preoperative Anxiety Using Visual Facial Anxiety Scale: An Alternative To The Verbal Rating Scale? Medical Research Archives. 2015;2(2).

75. Laufenberg-Feldmann R, Kappis B. Assessing preoperative anxiety using a questionnaire and clinical rating: a prospective observational study. Eur J Anaesthesiol. 2013;30(12):758-63.

76. Vadhanan P, Tripaty DK, Balakrishnan K. Pre-operatve anxiety amongst patents in a tertary care hospital in India- a prevalence study. Journal of Society of Anesthesiologists of Nepal. 2017;4 (1).

77. Brunault P, Jacobi D, Miknius V, Bourbao-Tournois C, Huten N, Gaillard P, et al. High preoperative depression, phobic anxiety, and binge eating scores and low medium-term weight loss in sleeve gastrectomy obese patients: a preliminary cohort study. Psychosomatics. 2012;53(4):363-70.

78. Yin Q-Y, Ma Z-S, Feng F-Y, Wang L-X. Postoperative anxiety and depression in patients undergoing thoracoscopic closure of congenital heart defects. J Cardiovasc Nurs. 2012;27(6):547-52.

79. Alattas SA, Smith T, Bhatti M, Wilson-Nunn D, Donell S. Greater pre-operative anxiety, pain and poorer function predict a worse outcome of a total knee arthroplasty. Knee Surgery, Sports Traumatology, Arthroscopy. 2017;25(11):3403-10.

80. Ali A, Altun D, Oguz BH, Ilhan M, Demircan F, Koltka K. The effect of preoperative anxiety on postoperative analgesia and anesthesia recovery in patients undergoing laparascopic cholecystectomy. Journal of anesthesia. 2014;28(2):222-7. 
81. Ali A, Lindstrand A, Sundberg M, Flivik G. Preoperative anxiety and depression correlate with dissatisfaction after total knee arthroplasty: a prospective longitudinal cohort study of 186 patients, with 4-year follow-up. J Arthroplast. 2017;32(3):767-70.

82. Bilberg R, Nørgaard B, Overgaard S, Roessler KK. Patient anxiety and concern as predictors for the perceived quality of treatment and patient reported outcome (PRO) in orthopaedic surgery. BMC Health Serv Res. 2012;12(1):244.

83. Maranets I, Kain ZN. Preoperative anxiety and intraoperative anesthetic requirements. Anesthesia Analgesia. 1999;87(6):1346.

84. Osborn TM, Sandler NA. The effects of preoperative anxiety on intravenous sedation. Anesth Prog. 2004;51(2):46.

85. Székely A, Balog P, Benkö E, Breuer T, Székely J, Kertai MD, et al. Anxiety predicts mortality and morbidity after coronary artery and valve surgery-a 4-year follow-up study. Psychosom Med. 2007;69(7):625-31.

86. Tully PJ, Baker RA, Turnbull D, Winefield $\mathrm{H}$. The role of depression and anxiety symptoms in hospital readmissions after cardiac surgery. J Behav Med. 2008;31(4):281-90.

87. Hathaway D. Effect of preoperative instruction on postoperative outcomes: a meta-analysis. Nursing research. 1986.

88. Ip HYV, Abrishami A, Peng PW, Wong J, Chung F. Predictors of postoperative pain and analgesic consumptiona qualitative systematic review. Anesthesiology: The Journal of the American Society of Anesthesiologists. 2009;111(3):657-77.

89. Laufenberg-Feldmann R, Kappis B, Schuster M, Ferner M. Relevance of preoperative anxiety for postoperative outcome in urological surgery patients: A prospective observational study. Schmerz (Berlin Germany). 2016;30(2):166-73.

90. Matthias AT, Samarasekera DN. Preoperative anxiety in surgical patients-experience of a single unit. Acta Anaesthesiologica Taiwanica. 2012;50(1):3-6.

91. Mclntosh S, Adams J. Anxiety and quality of recovery in day surgery: A questionnaire study using Hospital Anxiety and Depression Scale and Quality of Recovery Score. Int J Nurs Pract. 2011;17(1):85-92.

92. Wada S, Inoguchi H, Hirayama T, Matsuoka YJ, Uchitomi Y, Ochiai H, et al. Yokukansan for the treatment of preoperative anxiety and postoperative delirium in colorectal cancer patients: a retrospective study. Jpn J Clin Oncol. 2017;47(9):844-8.

93. Blackburn J, Qureshi A, Amirfeyz R, Bannister G. Does preoperative anxiety and depression predict satisfaction after total knee replacement? Knee. 2012;19(5):522-4.

94. Boeke S, Jelicic M, Bonke B. Pre-operative anxiety variables as possible predictors of post-operative stay in hospital. Br J Clin Psychol. 1992;31(3):366-8.

95. Pereira L, Figueiredo-Braga M, Carvalho IP. Preoperative anxiety in ambulatory surgery: The impact of an empathic patient-centered approach on psychological and clinical outcomes. Patient Educ Couns. 2016;99(5):733-8. 
96. Wongkietkachorn A, Wongkietkachorn N, Rhunsiri P. Preoperative needs-based education to reduce anxiety, increase satisfaction, and decrease time spent in day surgery: a randomized controlled trial. World journal of surgery. 2018;42(3):666-74.

97. Chunta KS. Expectations, anxiety, depression, and physical health status as predictors of recovery in open-heart surgery patients. J Cardiovasc Nurs. 2009;24(6):454-64.

\section{Figures}

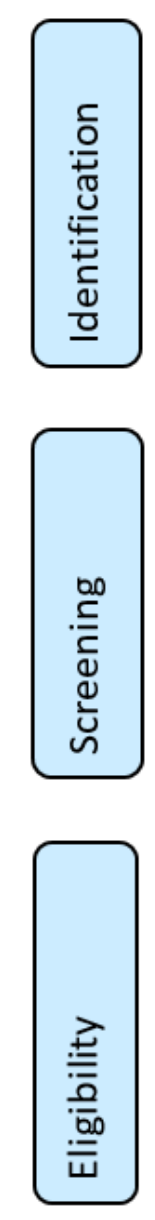

Records identified in PubMed/Medline (32), Science direct (743), LILACS (12)

Additional records identified through other sources $(n=65)$

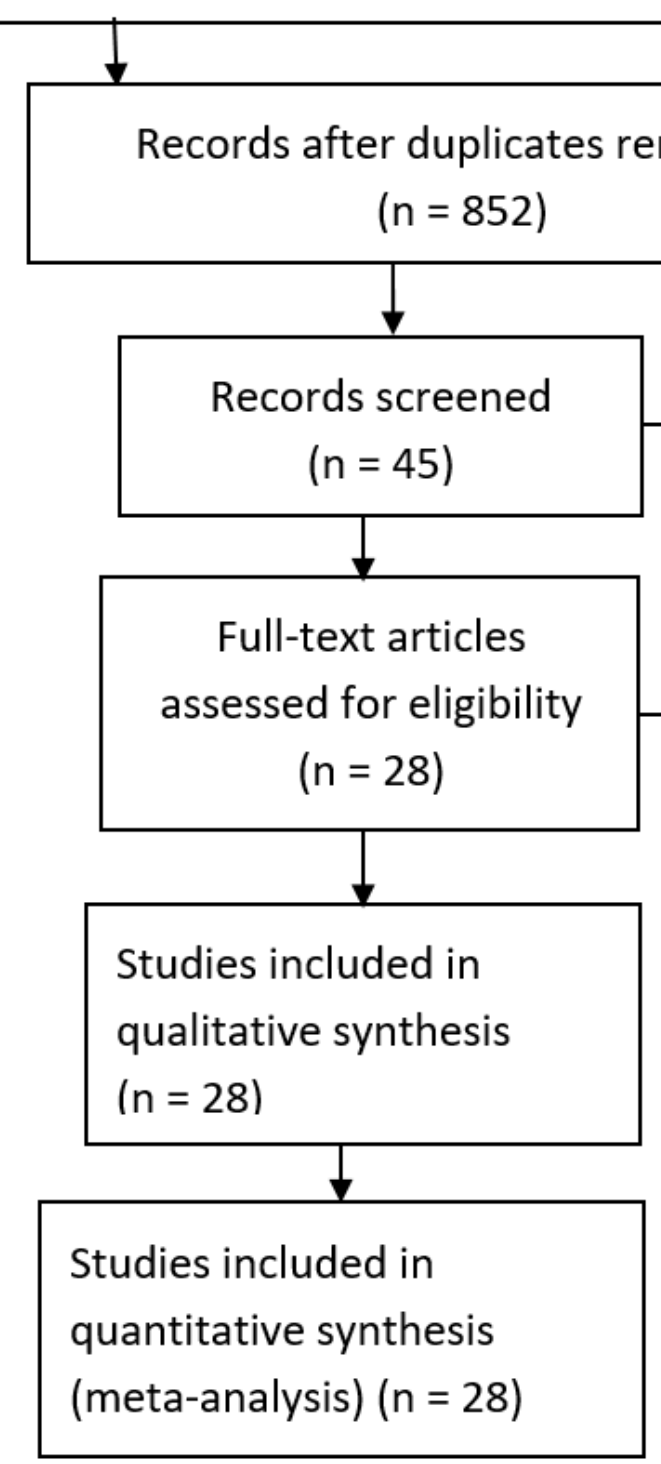

Records excluded $(n=812)$

Full-text articles excluded, with reasons ( $n=17$ )

\section{Figure 1}

Prisma flow chart 


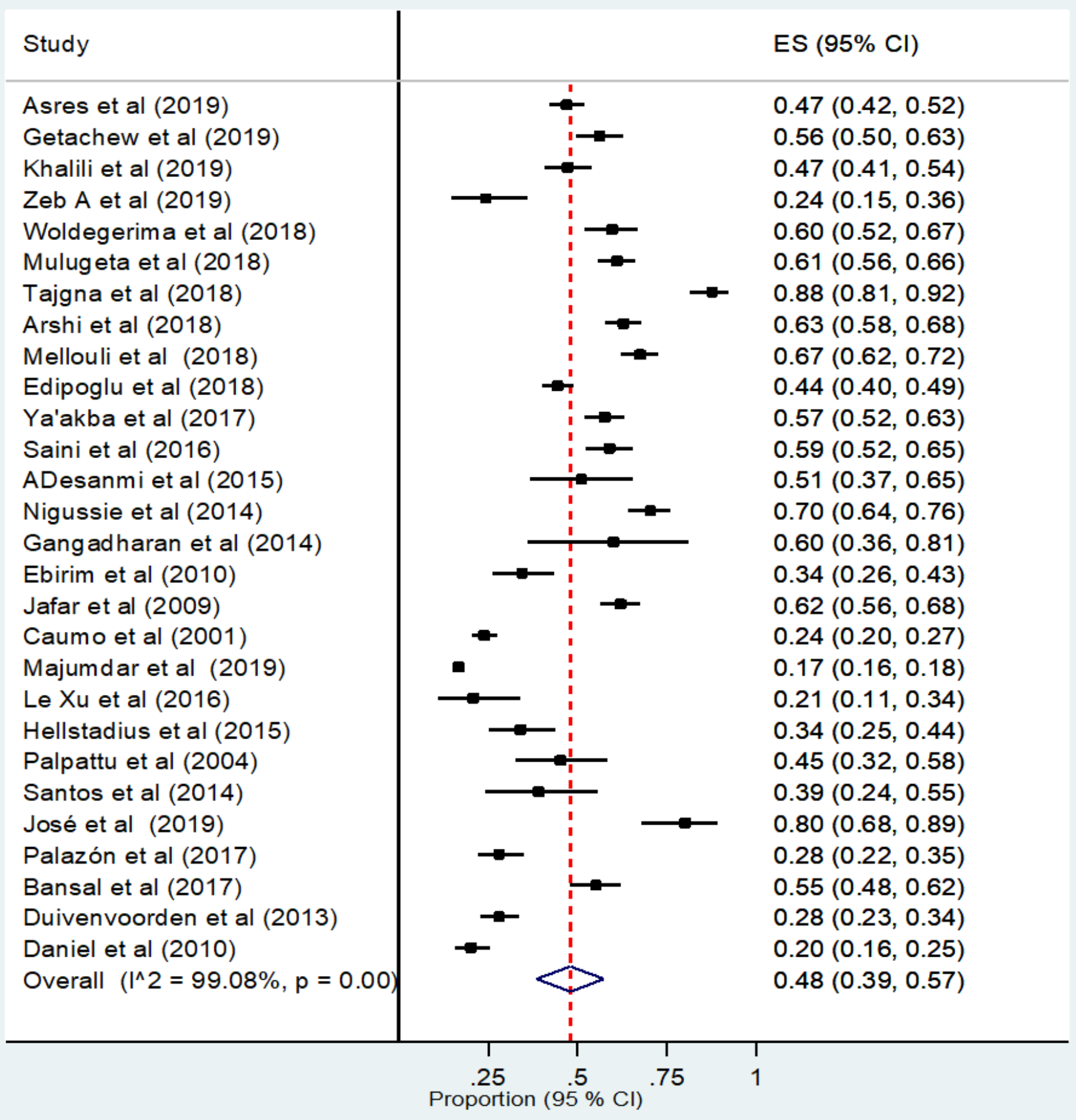

Figure 2

Forest plot for the global prevalence of preoperative anxiety: The midpoint of each line illustrates the prevalence; the horizontal line indicates the confidence interval, and the diamond shows the pooled prevalence 


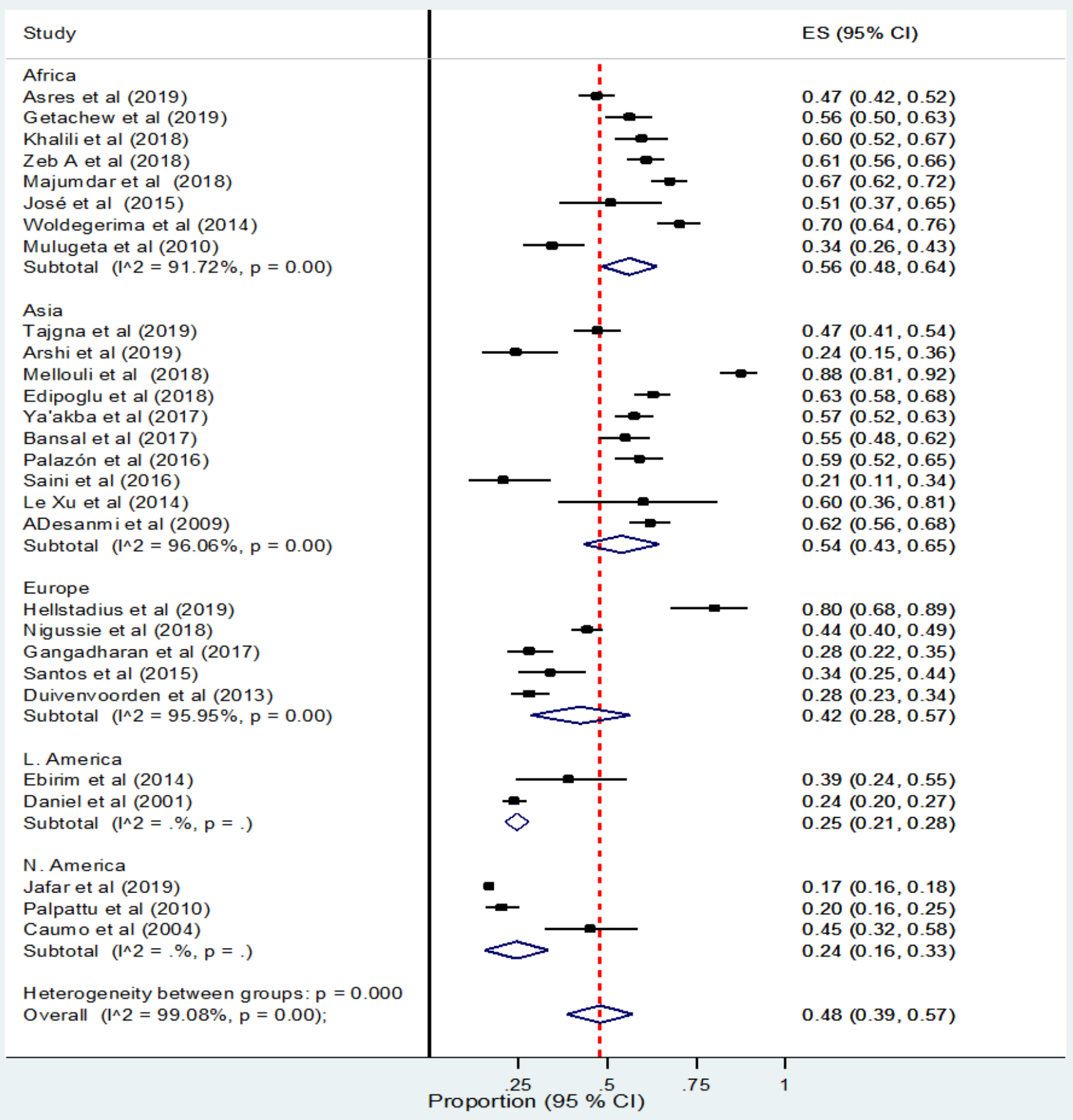

\section{Figure 3}

Forest plot for subgroup analysis of the global prevalence of preoperative anxiety by continent: The midpoint of each line illustrates the prevalence; the horizontal line indicates the confidence interval; the diamond shows the pooled prevalence. 


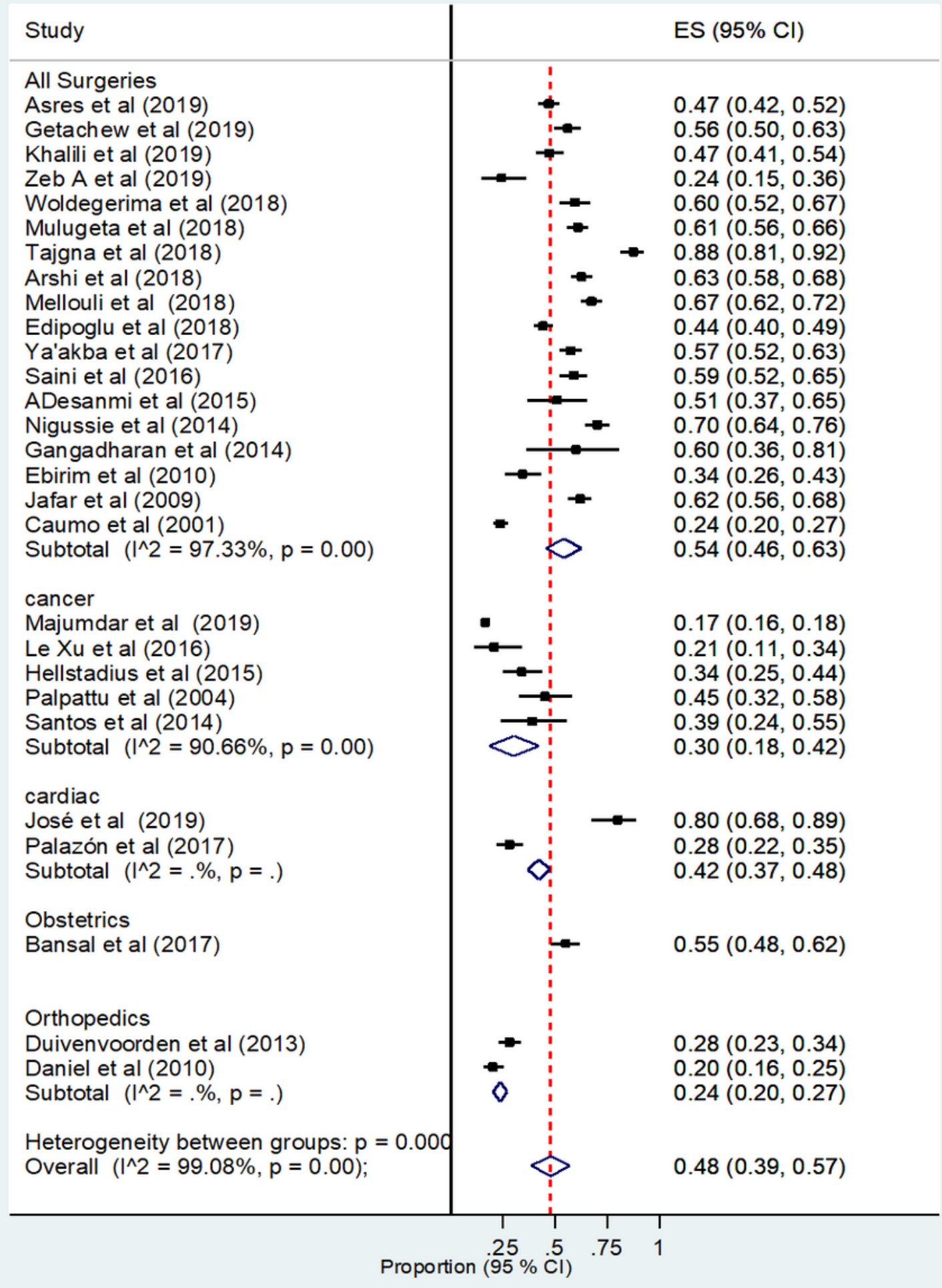

Figure 4

Forest plot for subgroup analysis of the global prevalence of preoperative anxiety with types of surgery: The midpoint of each line illustrates the prevalence; the horizontal line indicates the confidence interval; the diamond shows the pooled prevalence 

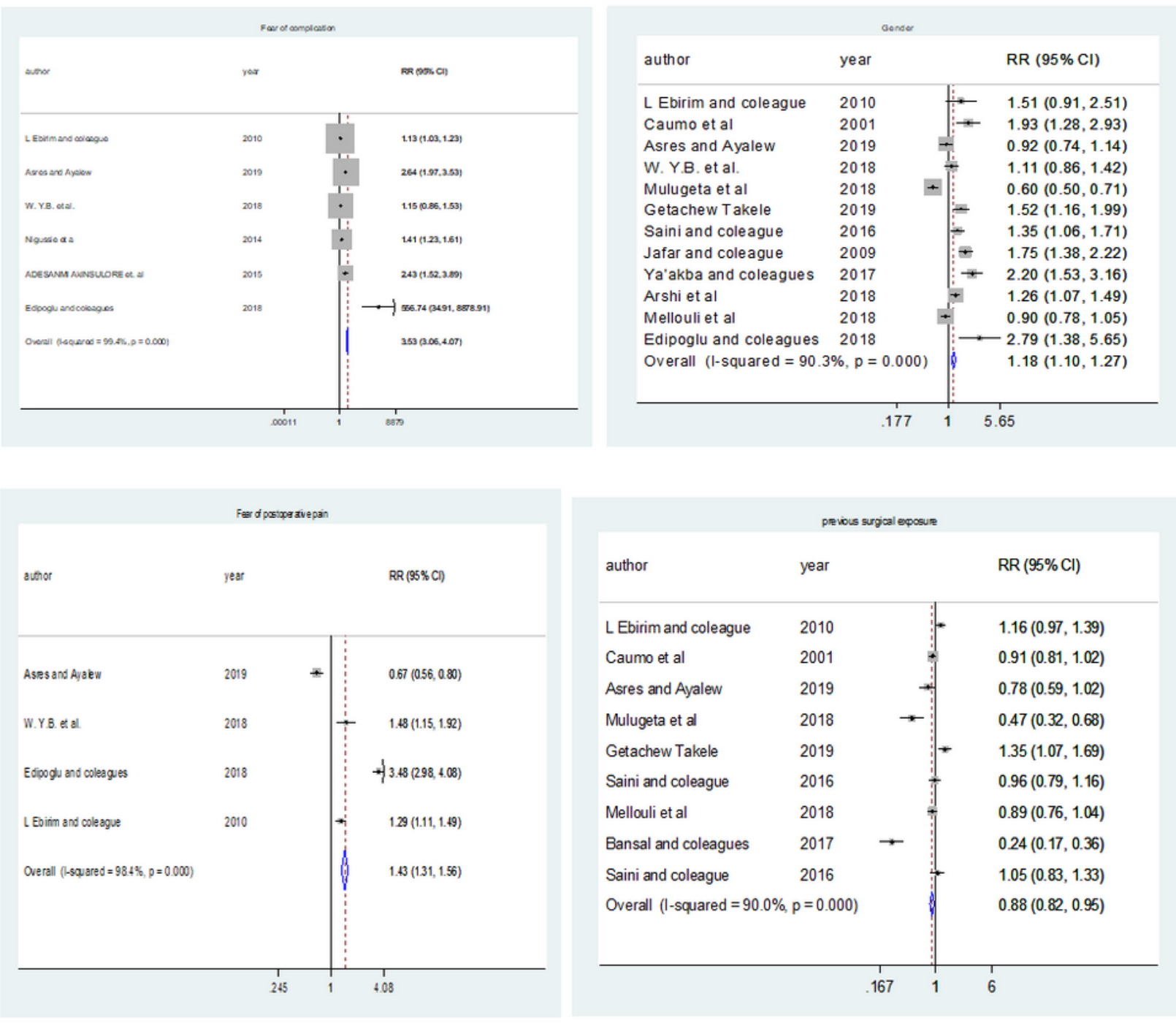

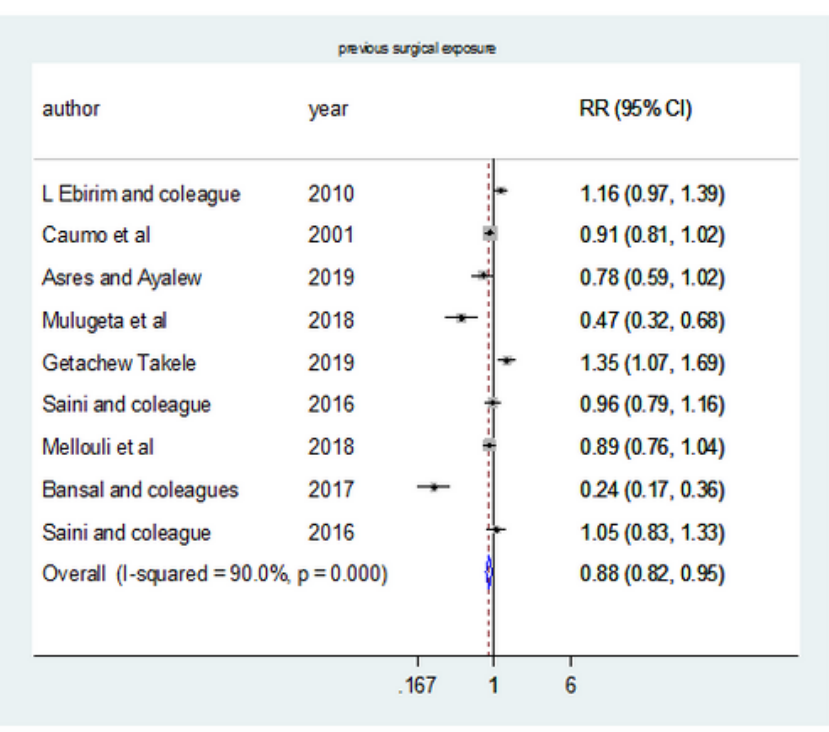
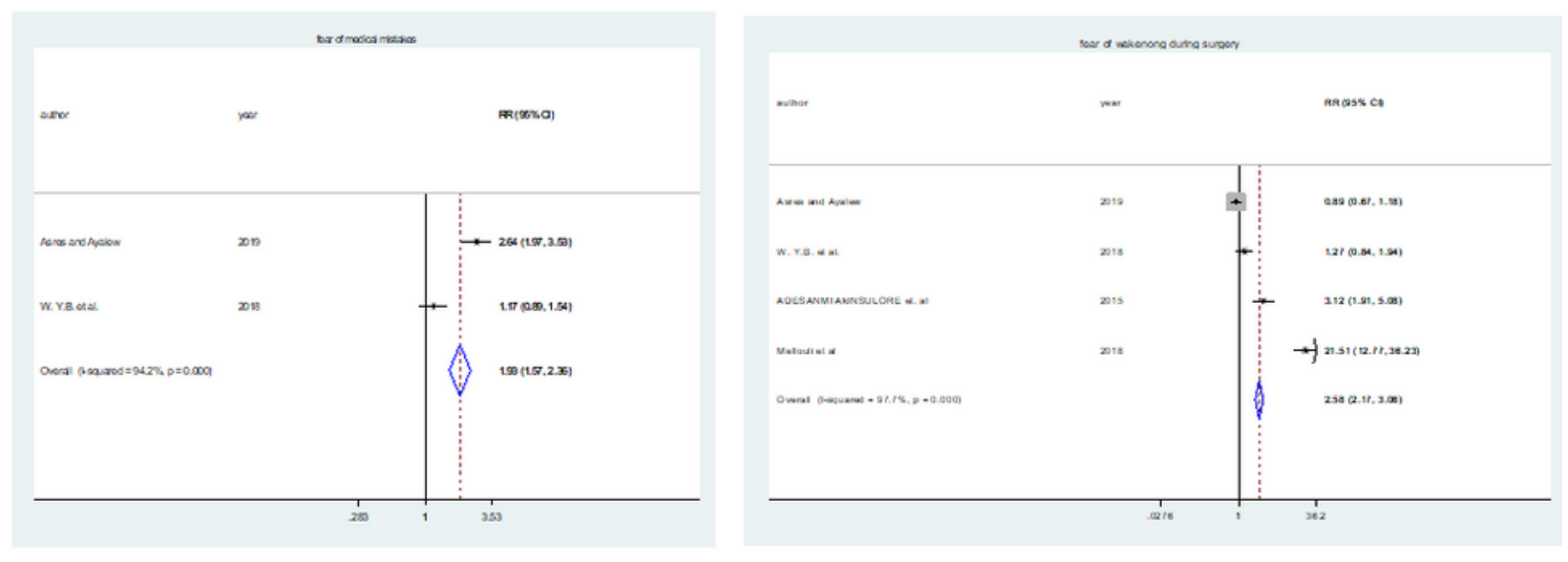

\section{Figure 5}

Forest plot showing pooled relative risk (log scale) of the associations between preoperative anxiety and its determinants (fear of complication, Gender, previous surgery, fear of medical mistakes, and fear of awaking during surgery respectively.

\section{Supplementary Files}


This is a list of supplementary files associated with this preprint. Click to download.

- suplementalTable2.docx

- prismachecklist.doc

- suplementalFig1.docx

- suplemntaltable1.docx 